\title{
Ensino de inglês na escola pública em perspectiva INdisciplinar e dialógica
}

\author{
English teaching in public schools \\ from an INdisciplinary and dialogical perspective
}

\author{
Samuel de Carvalho Lima \\ Instituto Federal do Rio Grande do Norte, Natal, Rio Grande do Norte, Brasil
}

\begin{abstract}
Resumo: Este artigo objetiva investigar como o discurso acadêmico do professor-pesquisador de inglês participa da discussão ideológica sobre o ensino de inglês na escola pública. À luz da Linguística Aplicada (LA) INdisciplinar, fundamento a discussão com concepções de ensino crítico de inglês no Brasil. Posteriormente, em interface com a perspectiva dialógica da linguagem, apresento minha postura dialógica de análise de dados para explorar a composição de dois resumos de dissertação de mestrado sobre o ensino de inglês publicados em 2017 e 2020. A análise do corpus evidencia que o discurso acadêmico se bivocaliza com o discurso teórico, por meio da nomeação de teorias e da citação indireta a outros estudos, para criticar a tradição de ensino de leitura e escrita em língua inglesa e complementar o discurso oficial sobre o ensino de inglês. Assim, a análise elucida a heterogeneidade da composição do discurso acadêmico do professorpesquisador de inglês e revela a ausência de interesse inicial sobre problemas sociais, mas que acabam sendo apontados no corpus analisado.
\end{abstract}

Palavras-chave: Ensino de inglês; Escola pública; Linguística Aplicada; Análise dialógica

\begin{abstract}
This paper aims to investigate how the academic discourse of the English teacher-researcher takes part in the ideological discussion about English teaching in public schools. In the light of INdisciplinary Applied Linguistics (AL), I ground the discussion with conceptions of critical teaching of English in Brazil. Subsequently, in an interface with the dialogical perspective of language, I present my dialogical approach to data analysis to explore the composition of two master's dissertation abstracts on English teaching published in 2017 and 2020. Corpus analysis shows that the academic discourse is bivocalized with the theoretical discourse, through naming theories and indirect citation to other studies, to criticize the tradition of teaching reading and writing in the English language and to complement the official discourse on English teaching. Thus, the analysis elucidates the heterogeneity of the composition of the academic discourse of the English teacher-researcher and reveals the absence of initial interest in social problems, but which end up being pointed out in the analyzed corpus.
\end{abstract}

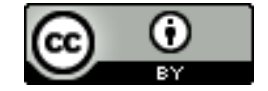


Keywords: English teaching; Public school; Applied Linguistics; Dialogical analysis

\section{Introdução}

Em uma perspectiva histórica, vale lembrar que, há mais de 20 anos, as relações sociais entre os sujeitos em sala de aula têm sido problematizadas pela transdisciplinaridade da LA brasileira. Celani (1998) aponta para o processo de aprendizagem no contexto de interação institucional como um dos objetos de investigação que reivindicam uma visão transdisciplinar face à complexidade dos fenômenos da pesquisa que tem a linguagem na sua base. No início do século XXI, a LA brasileira se INdisciplina, assumindo-se crítica - mestiça, ideológica, transgressiva - (MOITA LOPES, 2006). Sob o rótulo da criticidade, salientamos três compreensões: 1) a produtividade das pesquisas para a criação de inteligibilidades sobre o mundo em práticas situadas e com responsabilidade social por um sujeito cuja subjetividade e intersubjetividade o torna inseparável do conhecimento que produz; 2) a ética que norteia as investigações por meio do diálogo aberto imbuído de valores democraticamente definidos na esfera pública e da explicitação das razões pelas quais agimos; 3) a prática autorreflexiva continuada (FABRÍCIO, 2006, 2017; PENNYCOOK, 2006, 2018). Desse modo, assumo uma vertente INdisciplinar ${ }^{1}$ da LA que se caracteriza como crítica, responsável e solidária, que pauta desigualdades e injustiças sociais, articulando-se a pesquisas sobre ensino de inglês na escola pública para favorecer a autonomia de professores e estudantes que negociam e reinventam formas de ocupar o espaço-tempo social.

O interesse pelo ensino de inglês me levou a refletir sobre o desenvolvimento da competência da autonomia da aprendizagem no contexto da escola pública em Portugal. No âmbito da política transnacional de ensino de línguas da comunidade europeia, a autonomia da aprendizagem tem sido discutida pela pesquisadora portuguesa Flávia Vieira como um processo que se relaciona intimamente à aprendizagem da língua,

\footnotetext{
${ }^{1}$ A expressão INdisciplinar se refere à organização da primeira edição do livro intitulado Por uma Linguística Aplicada INdisciplinar, com IN em maiúsculo, em 2006, pelo professor/pesquisador Luiz Paulo da Moita Lopes. Considero essa obra seminal na conscientização sobre a politização do ato de realizar pesquisas no âmbito dos estudos em LA no Brasil, de modo que sua contribuição permanece impactando a autorreflexão própria da área até hoje.
} 
podendo ser flagrado no livro didático (VIEIRA; MARQUES; MOREIRA, 1999). Essa concepção foi revisitada em 2017-2018, no âmbito de meu estágio de pós-doutoramento, quando aproximamos a perspectiva europeia da perspectiva brasileira freiriana para a promoção da autonomia da aprendizagem para além dos muros da escola pública e flagramos uma baixa incidência do processo de reflexão sobre o eu-do-aluno na análise de material didático para o ensino de língua inglesa em nível médio/secundário nas escolas portuguesas investigadas (LIMA; VIEIRA, 2020). Os dados dessa investigação denunciaram ainda, por meio da visibilidade das vozes das professoras da escola pública, a existência de uma cultura escolar de controle e reprodução, resistente a mudanças ${ }^{2}$. As professoras portuguesas reconhecem a importância do desenvolvimento da pedagogia para a autonomia e discutem a necessidade de sua complementação com estratégias centradas no aluno. A realização dessa pesquisa me permitiu compreender a importância do eu-do-aluno em outro tempo e espaço, isto é, no contexto de ensino de inglês na escola pública no nordeste brasileiro, de modo a poder dar visibilidade a pequenas histórias, sem ingenuidades, e reconhecer que "[...] nem sempre as teorias e abordagens gestadas na Metrópole atendem aos interesses da periferia” (RAJAGOPALAN, 2013, p. 154).

Orientado pela prática autorreflexiva continuada da LA, este artigo objetiva investigar como o discurso acadêmico do professor-pesquisador de inglês participa da discussão ideológica sobre o ensino de inglês na escola pública. Para dar conta desse objetivo, o texto se divide em mais 4 seções a seguir. Na próxima seção, à luz da LA INdisciplinar, fundamento a discussão com concepções de ensino crítico de inglês no Brasil. Na sequência, em interface com a perspectiva dialógica da linguagem, apresento minha postura dialógica de análise de dados. Posteriormente, exploro a composição de dois resumos de dissertação de mestrado sobre o ensino de inglês publicados em 2017 e 2020. Por fim, apresento minhas considerações finais.

\footnotetext{
${ }^{2}$ A experiência de internacionalização com a pesquisa sobre o ensino de inglês na escola pública em Portugal me desafiou, pela primeira vez, a refletir sobre os pontos de vista de professoras de língua inglesa sobre o livro didático e sua atuação profissional, promovendo meu interesse, hoje, pela análise dialógica do discurso acadêmico do professor de inglês que exerce sua profissão em países lusófonos.
} 


\section{Ensino crítico de inglês no Brasil}

Pressupondo que "o educador já não é o que apenas educa, mas o que, enquanto educa, é educado, em diálogo com o educando que, ao ser educado, também educa" (FREIRE, 2019, p. 95-96), optamos por compreender a escola como um lugar de esperança, intimamente ligada à sociedade, podendo promover interações para a manutenção ou para a transformação social. Nessa tensão, juntamente com Gadotti (2007), optamos por defender uma escola pública transformadora, pois é o espaço em que nos encontramos para estudar, conversar, discutir e fazer política. Além disso, partimos da compreensão de língua inglesa apresentada por Rajagopalan (2018) - World English -, pois ela leva em consideração os impactos da globalização, que não podem ser negados na sociedade, ou seja, as mudanças com que lidamos em relação a nossa própria nacionalidade, nossa língua nacional e, consequentemente, nossa própria existência. Essa compreensão também implica o reconhecimento de que nos tornamos indivíduos transnacionais por meio de movimentos migratórios em virtude do trabalho e grandes corporações, ou por meio de movimentos de refugiados, ou por meio do deslocamento tempo/espaço oportunizado pelo uso de tecnologias digitais.

Parte da discussão acadêmica sobre o ensino de inglês no Brasil tem sido realizada sob o viés de uma educação crítica, corporificando-se, inclusive, em uma Linguística Aplicada Crítica, Transgressiva, INdisciplinar, em diálogo, sobretudo, mas não exclusivamente, com Hooks (1994) e Pennycook (2006, 2007, 2010, 2018). As concepções de ensino crítico de inglês no Brasil ora dialogam com os princípios operacionais de um pós-método (KUMARAVADIVELU, 2012, 2016), ora permanecem na relação entre abordagens imperialistas e pedagogias críticas. Kumaravadivelu (2016, p. 68) denuncia as "forças sutilmente invisíveis e aparentemente invencíveis" que tem operado antes e durante o século XXI para promover discriminação e desigualdade na área de ensino de língua inglesa. Para o autor, essas forças criam o mito do falante nativo como o único sujeito possivelmente reconhecido por sua expertise em métodos e materiais para o ensino de inglês. Em perspectiva contra-hegemônica, o autor mobiliza a comunidade subalterna ao reivindicar um conjunto de ações coletivas, coordenadas e sincronizadas com o potencial de tensionar com a estrutura social que sistematicamente promove assimetrias por meio de relações políticas, culturais, econômicas e educacionais. 
Reconhecemos que as concepções de ensino crítico de inglês no Brasil têm sido reportadas por pesquisas de professores-pesquisadores de inglês brasileiros que relacionam o ensino-aprendizagem de inglês a problemas sociais. Urzeda-Freitas (2012) critica a prática de ensino de inglês que contempla prioritariamente atividades lúdicas e comunicativas. O professor-pesquisador constrói, por meio da condução de leitura e discussão de textos, vídeos e figuras em sala de aula, possibilidades para uma aprendizagem de inglês comprometida com temas como globalização, corpo, raça, classe, cultura, identidade, gênero social e sexualidade. $\mathrm{O}$ autor constata que debater temas polêmicos com estudantes brasileiros de inglês causa, inicialmente, um necessário choque com o novo, um possível desconforto. No entanto, embora inicialmente desconfortável, a reflexão produzida pelo professor-pesquisador mostra que essas iniciativas favorecem o desenvolvimento não apenas dos estudantes, mas também do próprio professor, que necessita refletir criticamente sobre sua própria prática pedagógica, revisitar suas aprendizagens e privilégios e lidar com insatisfações. Sua pesquisa foi realizada em um centro de línguas da Universidade Federal de Goiás e, a partir dela, Urzeda-Freitas (2012, p. 95, grifo nosso) nos convida a refletir sobre essa abordagem no contexto das escolas regulares brasileiras, prevendo que “[...] talvez esse seja um dos maiores desafios da Linguística Aplicada no século XXI: (re)descobrir o lugar das aulas e dos(as) professores(as) de LE na construção de um mundo mais democrático e livre”.

Rocha (2013) realiza uma pesquisa-ação em uma turma de $1^{\circ}$ ano do ensino médio em uma escola pública federal no Rio de Janeiro. A autora desenvolve sua pesquisa com base no pressuposto de que a condução e o relato de sua investigação representam uma realidade possível, entre outras também possíveis, considerando a realidade como "um modo de se falar sobre ela" (ROCHA, 2013, p. 101). A professora-pesquisadora desenvolve uma proposta pedagógica com uma visão problematizadora sobre sexualidades, juntamente com seus estudantes, meninas e meninos entre 14 e 18 anos, com o rigor ético publicamente defendido por uma LA INdisciplinar.

Orientado por uma discussão sobre subalternidade e ideologia contra-hegemônica, Mulico (2020) faz o tratamento das concepções de trabalho, esforço e sucesso no âmbito do ensino de inglês em uma turma de curso técnico de nível médio de uma instituição de educação profissional. No contexto da educação profissional, o autor denuncia a lacuna da produção de materiais problematizadores que sejam norteados por uma educação 
crítica para a cidadania. Vale destacar que as instituições pertencentes à Rede Federal de Educação Profissional, Científica e Tecnológica (RFEPCT) são motivadas pelas possibilidades de transformação social e apontadas, conforme reivindica Ciavatta (2014), como uma educação com a qualidade necessária para um futuro de superação da dualidade de classes sociais. No âmbito da educação profissional, a discussão sobre o mundo do trabalho e sobre classes sociais em uma perspectiva histórica, muitas vezes, ganha precedência, embora já estejamos avançando para uma perspectiva de maior interseccionalidade, conforme é possível perceber na discussão oportunizada pelo autor, que sugere textos para o design de materiais críticos, em que raça e gênero social são problematizados por meio do locus de enunciação e da necessidade de o professorpesquisador desaprender seus privilégios.

Também atuando no contexto da RFEPCT, Da Silva (2020) propõe atividades críticas para o ensino de inglês por meio da articulação entre uma abordagem baseada em tarefas e pedagogias críticas. O professor-pesquisador problematiza a questão de gênero social no mundo do trabalho juntamente com 20 estudantes do Instituto Federal de Santa Catarina e defende a concepção de uma educação profissional comprometida com a inclusão, a igualdade e a justiça social. A proposta do autor promove uma leitura possível sobre a eficiência da abordagem baseada em tarefas ao relacionar planejamento e desenvolvimento e ao discutir os momentos adversos e as estratégias de superação desses momentos em sala de aula. No entanto, fica evidente que a disciplinaridade da abordagem baseada em tarefas acaba por subordinar a reflexão crítica apenas para o momento final da atividade.

Caetano (2020) relaciona a abordagem comunicativa ao pós-método para elaborar atividades sob a perspectiva do ensino crítico de inglês. A autora ainda estabelece uma aproximação entre a teoria sobre o letramento crítico e a prescrição dos documentos oficiais para ensino de línguas estrangeiras no Brasil, mais especificamente as Orientações Curriculares para o Ensino Médio, contexto de aprendizagem de inglês objeto de sua reflexão. O diálogo teórico proposto por Caetano (2020), articulado ao discurso oficial sobre o ensino de inglês, isto é, as orientações curriculares, reivindica um tratamento especial para a compreensão sobre as identidades dos participantes do processo de ensino-aprendizagem de inglês.

Revista da Anpoll, Florianópolis, v. 52, n. 2, p. 138-156, jun.-out., 2021 | 143 
Com base nessas pesquisas, flagramos concepções de ensino crítico de inglês no Brasil. De modo geral, sob o rótulo da criticidade, as pesquisas articulam o ensino de inglês a discussões sobre cidadania, participação social e desigualdades, em perspectiva de interseccionalidade com raça, gênero social e sexualidade. Destacamos que o debate sobre as concepções de ensino crítico de inglês não se pretende exaustivo, pois reconhecemos que outros pesquisadores têm realizado o levantamento de outras possibilidades, fazendo desse levantamento um objeto de investigação per se, ao destacar pesquisas sobre o ensino de inglês na escola pública em viés crítico, de modo a problematizar questões identitárias, sociais e políticas (CARNEIRO, 2021). De todo modo, esses estudos produzem realidades possíveis e nos convidam ao diálogo reflexivo sobre a prática de (pesquisa em) ensino de língua inglesa de modo a evitar o que Rajagopalan (2006) denuncia como ingenuidade metateórica. Motivado pela prática autorreflexiva continuada da LA crítica, em interface com a perspectiva dialógica da linguagem, parto para a explicitação da postura dialógica de análise de dados.

\section{Uma postura dialógica}

Segundo Brait (2016), abordar enunciados/textos levando em consideração o conjunto da obra de Bakhtin e o Círculo (Volóchinov, Medvedev e outros participantes) motivou o que hoje se denomina análise/teoria dialógica do discurso, perspectiva que tem se demonstrado bastante produtiva no Brasil (BRAIT, 2016, 2017). A pesquisadora salienta que uma análise dialógica do discurso não pode se configurar em uma proposta fechada e linearmente sistematizada. Ao contrário disso, essa teoria se constitui um conjunto de conceitos "que especificam a postura dialógica diante do corpus discursivo, da metodologia e do pesquisador" (BRAIT, 2016, p. 29, grifo da autora).

No conjunto de conceitos que podem orientar uma Análise Dialógica do Discurso (ADD), interessa-nos, particularmente, o de enunciado, pois, em perspectiva dialógica, o enunciado/texto é considerado o dado primário da análise linguística, filológica, literária e das Ciências Humanas em geral, uma vez que "Se concebe o texto no sentido amplo como qualquer conjunto coerente de signos [...] pensamentos sobre pensamentos, vivências das vivências, palavras sobre palavras, textos sobre textos" (BAKHTIN, 2016, p. 71-72). Além disso, conforme nos ensina Volóchinov (2017, p. 218-219, grifo do 
autor), a realidade da linguagem é "[...] o acontecimento social da interação discursiva que ocorre por meio de um ou de vários enunciados". Desse modo, assumo a perspectiva dialógica da linguagem que pressupõe o diálogo tanto como uma forma específica da comunicação discursiva, a mais importante, a exemplo do diálogo face a face (sentido estrito), quanto como qualquer comunicação discursiva (sentido amplo), pois todo discurso é inevitavelmente orientado para outros discursos e participa "[...] de uma espécie de discussão ideológica em grande escala: responde, refuta, ou confirma algo, antecipa as respostas e críticas possíveis, busca apoio e assim por diante" (VOLÓCHINOV, 2018, p. 219).

Em perspectiva dialógica, a linguagem enquanto prática social é concebida como discurso materializado por meio de suas unidades do fluxo discursivo, isto é, os enunciados que respondem a algo e se orientam para uma resposta. Por isso, para Bakhtin (2018), todo discurso é bivocal ${ }^{3}$, pois carrega diferentes posicionamentos e valorações sociais; a presença do outro no enunciado é marcada por diversos pontos de vista de modo que as relações dialógicas são possíveis entre enunciados distintos ou até mesmo entre palavras em um mesmo enunciado, desde que estas sejam tomadas como "representante do enunciado de um outro, ou seja, se ouvirmos nela a voz do outro" (BAKHTIN, 2018, p. 210).

O uso da linguagem, em perspectiva dialógica, está relacionado aos campos da atividade humana, sendo que, para Bakhtin (2016, p. 12, grifo do autor), “[...] cada campo de utilização da língua elabora seus tipos relativamente estáveis de enunciados, os quais denominamos gêneros do discurso". A perspectiva dialógica da linguagem pressupõe que todo enunciado possui um autor que, ao dar conta de sua intenção discursiva, determina a conclusibilidade de seu enunciado: a escolha do objeto, os limites e a exauribilidade semântico-objetal. Enquanto unidade da comunicação discursiva, os limites de cada enunciado são definidos pela alternância dos sujeitos que participam do diálogo.

Levando isso em consideração, na interface entre a LA na modernidade recente e a perspectiva dialógica da linguagem, encontro possibilidades para explorar como o discurso acadêmico do professor-pesquisador de inglês participa da discussão ideológica

\footnotetext{
${ }^{3}$ Todo discurso surge nas condições da comunicação dialógica, isto é, em relação ao discurso do outro. Todo discurso carrega, simultaneamente, o discurso do outro, tangenciando-se com ele. Assim, o discurso alheio é introduzido no nosso discurso a partir da nossa compreensão e avaliação, bivocalizando-se com nosso discurso.
}

Revista da Anpoll, Florianópolis, v. 52, n. 2, p. 138-156, jun.-out., 2021 | 145 
sobre o ensino de inglês na escola pública. Destaco, ainda, que essa interface se encontra alinhada a recentes trabalhos que celebram os 30 anos da Associação de Linguística Aplicada do Brasil (ALAB), ao discutirem os desafios, rupturas e possibilidades de pesquisa em LA, apontando relações possíveis entre a LA INdisciplinar e os estudos da linguagem em perspectiva dialógica (SZUNDY; MARTINS; MOREIRÃO, 2020; AMARAL; SILVA; GONÇALVES, 2020).

Para a análise dialógica, a exemplo do estudo de Lima e Bastos (2021), quando investigamos como o discurso jornalístico constitutivo de títulos e leads de notícias se torna palco de disputa de diversos pontos de vista ao utilizar diferentes vozes sociais, replico aqui a mesma postura dialógica para explorar resumos de dissertações de mestrado sobre o ensino de inglês na escola pública. Assim, inicio as reflexões a partir da análise das interações sociais entre os interlocutores, levando em consideração as condições de produção dos enunciados; em seguida, analiso as formas que os enunciados assumem; por último, realizo a análise linguística habitual para a elucidação das relações dialógicas situadas no campo do discurso. Desse modo, tenho interesse em evidenciar como o discurso acadêmico do professor-pesquisador de inglês participa da discussão ideológica sobre o ensino de inglês no Brasil por meio da composição dos resumos de dissertações que sintetizam suas pesquisas científicas. Para isso, no âmbito da análise, pressupomos que o discurso acadêmico do professor-pesquisador de inglês se bivocalize com, pelo menos, mais dois discursos que, nesta investigação, compreendemos como: 1) o discurso oficial sobre o ensino de inglês, isto é, os documentos que norteiam o ensino de língua inglesa no país e, em contexto mais imediato, da instituição em que a pesquisa do professor é realizada (leis, decretos, portarias, documentos institucionais, programas de curso, entre outros), por estarem diretamente relacionados à prática profissional do professor de inglês; 2) o discurso teórico, isto é, teorias e conceitos teórico-metodológicopedagógicos mobilizados para a realização da investigação no campo da atividade científica.

Seguindo os procedimentos assinalados, o corpus desta investigação é constituído por 2 resumos de dissertações de mestrado que sintetizam pesquisas sobre o ensino de inglês na escola pública. A constituição do corpus foi resultado da seleção de pesquisas realizadas sob minha orientação no último quadriênio - 2017 a 2020 - que se demonstraram mais representativas para a elucidação de como o discurso acadêmico do 
professor de inglês se compõem por meio da bivocalização com o discurso oficial sobre o ensino de inglês e o discurso teórico. Além disso, essa seleção possibilita a construção de uma (auto)crítica como uma das formas de promover uma LA continuamente autorreflexiva. Na próxima seção, ilustro a análise com os 2 resumos na íntegra para, posteriormente, retomar excertos do texto de modo a elucidar sua composição. Os resumos sintetizam dissertações defendidas no âmbito do Programa de Pós-Graduação em Ensino (POSENSINO) de modo a se constituírem tipos relativamente estáveis de enunciado cujo objetivo, compartilhado no campo da atividade científica, é apresentar as principais informações da dissertação para a comunidade acadêmica. Vale salientar que, no Brasil, tratar os resumos de dissertações como exemplares de gêneros do discurso da esfera acadêmica e objeto de investigação dos estudos linguísticos possui longa tradição (BIASI-RODRIGUES, 1999). Dito isso, passo para a análise das relações dialógicas que constituem o corpus da investigação.

\section{Discurso acadêmico de professoras-pesquisadoras de língua inglesa}

As relações dialógicas que o professor-pesquisador estabelece com a tradição acadêmica por meio do resumo de dissertação não se restringem aos interlocutores mais imediatos que avaliam seu trabalho - a banca examinadora da dissertação -, mas se ampliam a demais pesquisadores em nível (inter)nacional, pois seu resumo circula em diversas páginas/plataformas digitais na internet. Mesmo antes da dissertação aprovada, o resumo da dissertação é compartilhado como forma de convite automático enviado por e-mail à comunidade acadêmica local, quando o cadastro da defesa de dissertação é realizado; após a publicação da dissertação, o resumo passa a circular na própria página do programa de pós-graduação, na página de repositórios institucionais, na página do Catálogo de Teses e Dissertações (Plataforma Sucupira) da Coordenação de Aperfeiçoamento de Pessoal de Nível Superior (CAPES), vinculada ao Ministério da Educação do Brasil, entre outras páginas/plataformas da internet. Por isso, ciente da ampla circulação do resumo de dissertação de mestrado, o autor do texto o escreve consciente de que a leitura do resumo pelo seu interlocutor pode se constituir um convite à leitura de demais seções da dissertação ou da dissertação na íntegra. Os resumos, tomados como enunciados nesta análise, refletem as condições concretas de produção de pesquisa acadêmica de duas 
professoras-pesquisadoras de inglês de escolas públicas federais de ensino médio localizadas no interior do estado do Rio Grande do Norte: Mossoró e Apodi.

Tendo em vista a estabilidade das interações sociais no campo da atividade acadêmica, as formas que esses enunciados assumem também são relativamente estáveis. Ao sintetizar um texto relativamente extenso, isto é, exemplar do gênero do discurso dissertação de mestrado, em 371-469 palavras, as professoras-pesquisadoras de inglês compõe seu resumo de dissertação de modo a corresponder às expectativas da tradição acadêmica ao produzir o conhecimento científico, reportando o objetivo, a fundamentação teórica, a metodologia, os resultados e a conclusão de sua pesquisa ao passo que seleciona, criteriosamente, formas de condensar o que avalia como mais importante da dissertação por meio de frases/orações concisas e objetivas.

A análise do corpus revelou que o discurso acadêmico das professoraspesquisadoras bivocaliza-se com o discurso teórico para criticar a tradição de ensino de leitura e escrita em língua inglesa e complementar o discurso oficial sobre o ensino de inglês. Vejamos a composição do primeiro resumo. 
Figura 1 - Resumo de dissertação sobre o ensino de inglês para fins específicos. Com a necessidade do desenvolvimento de diversas áreas em uma época de evolução tecnológica, o Inglês para Fins Específicos (English for Specific Purposes - ESP) emergiu nos EUA durante a década de 1960 (HUTCHINSON \& WATERS, 1987). No Brasil, o ESP começou a se desenvolver durante a década de 1970, com o Projeto Nacional Brasileiro de ESP, coordenado pela professora Antonieta Celani e, mesmo após quatro décadas, o ESP ainda tem sido entendido como um curso de leitura para áreas específicas (RAMOS, 2008). O propósito desta pesquisa é trazer uma proposta de reflexão-ação para o ensino de ESP para a Educação Profissional e Tecnológica (EPT) e elucidar a forma como o ESP tem sido ensinado no Instituto Federal de Educação, Ciência e Tecnologia do Rio Grande do Norte (IFRN). A partir de um estudo documental-exploratório, analisamos os programas de dez cursos técnicos na modalidade subsequente, com foco no programa da disciplina, considerando os princípios básicos das teorias de ESP e dos Multiletramentos (HUTCHINSON \& WATERS, 1987; DUDLEY-EVANS, 1998; C NEW LONDON GROUP, 1996; COPE \& KALANTZIS, 2009), desenvolvendo uma proposta que considerou, também, aspectos relacionados aos gêneros discursivos (SWALES, 1990; SWALES1998). Aplicamos, então, um questionário com os alunos do Curso Técnico em Petróleo e Gás e duas entrevistas semiestruturadas com dois professores do curso: o professore de ESP e um engenheiro responsável por disciplinas da área técnica. A análise dos dados nos levou a nossa proposta, construído para ser utilizado como um guia por professores que trabalham com o inglês em contextos de EPT. A proposta é inspirada em uma sequência didática, dividido em: estudo do gênero que atenda às necessidades dos alunos, elaboração do gênero pelos alunos, fases com características sociolinguísticas e a reelaboração do gênero pelos alunos (DOLZ, NOVERRAZ \& SCHNEWLY, 2004). As seções da proposta foram elaboradas considerando o que os professores destacaram como um bom curso de ESP, as lacunas que encontramos no programa da disciplina no que se refere ao ESP e aos multiletramentos, bem como as opiniões dos alunos. Alguns dos nossos resultados apontaram para o fato de que o ensino de ESP no IFRN ainda é voltado para atividades de leitura e tradução, privilegiando gêneros acadêmicos como o artigo e o abstract; que a língua estrangeira deveria ser trabalhada tanto a partir de leituras como de produções orais, de acordo com os alunos e os professores entrevistados, além da importância do trabalho com a leitura; e alguns pontos colocados pelos professores, como o ensino colaborativo e a carga horária da disciplina. A proposta aqui apresentada não é um manual que possui as melhores possibilidades para o ensino de ESP na EPT, mas um guia que pretende ir além do que está posto nos currículos de ESP que contam com uma prática pedagógica que se preocupa (quase que exclusivamente) com a leitura e vocabulário.

Fonte: Guerra (2017).

Neste resumo (Figura 1), ao tomarmos as duas primeiras orações constitutivas, percebemos que a professora-pesquisadora tematiza o Inglês para Fins Específicos (ESP) em resposta ao seu desenvolvimento nos Estados Unidos e no Brasil. O discurso acadêmico da professora-pesquisadora, ao bivocalizar com o discurso teórico por meio da citação indireta a outros estudos que discutem o ESP, critica a tradição de ensino de leitura (curso de leitura para áreas específicas), o que ela avalia como ultrapassado por 
meio do jogo de palavras/expressões mesmo após e ainda no excerto: mesmo após quatro décadas, o ESP ainda tem sido entendido como um curso de leitura. Desse modo, a professora-pesquisadora demonstra possuir uma compreensão sobre o ESP que diverge dessa tradição, o que justifica o objetivo apresentado que se endereça a demais professores de inglês e pesquisadores sobre o ensino de inglês: O propósito desta pesquisa é trazer uma proposta de reflexão-ação para o ensino de ESP para a Educação Profissional e Tecnológica (EPT) e elucidar a forma como o ESP tem sido ensinado no Instituto Federal de Educação, Ciência e Tecnologia do Rio Grande do Norte (IFRN).

Quando o discurso acadêmico da professora se bivocaliza com o discurso teórico sobre a literatura acerca do ESP da década de 80, uma pedagogia mais contemporânea (Pedagogia dos Multiletramentos) e uma concepção de gêneros do discurso, tanto por meio da inserção do referente no texto quanto por meio da filiação conceitual explícita ao usar o verbo considerar (Considerando os princípios básicos das teorias de ESP e dos Multiletramentos; que considerou, também, aspectos relacionados aos gêneros discursivos), com o propósito de realizar uma análise documental-exploratória, o discurso acadêmico endereça sua crítica ao discurso oficial da oferta de inglês da instituição (programas de dez cursos técnicos). O discurso acadêmico reafirma sua crítica à tradição do ensino de ESP refletido no discurso oficial da instituição por meio da explicitação dos resultados da investigação que avaliam a oferta como antiquada por meio do uso da palavra ainda e julga que o programa apresenta lacunas: Alguns dos nossos resultados apontaram para o fato de que o ensino de ESP no IFRN ainda é voltado para atividades de leitura e tradução; as lacunas que encontramos no programa da disciplina no que se refere ao ESP. Desse modo, o discurso acadêmico aponta para a necessidade de uma complementariedade ao que está posto pelo discurso oficial por meio do uso do advérbio além, percebido no excerto: um guia que pretende ir além do que está posto nos currículos de ESP. Por fim, destaco que, embora a professora-pesquisadora busque contemplar diferentes perspectivas em sua pesquisa, tanto em termos teóricos quanto em relação aos sujeitos participantes (estudantes, professores, engenheiros), a criticidade do discurso acadêmico não contempla a discussão sobre problemas sociais, cidadania, participação social e desigualdades, em perspectiva de interseccionalidade com raça, gênero social e sexualidade, conforme agenda de uma vertente mais radical da LA. Vejamos o próximo exemplar.

Revista da Anpoll, Florianópolis, v. 52, n. 2, p. 138-156, jun.-out., 2021 | 150 
Figura 2 - Resumo de dissertação sobre o ensino de escrita colaborativa em inglês. A prática da escrita em língua inglesa no espaço do ensino médio das escolas públicas está restrita, muitas vezes, a tarefas de tradução ou exercícios repetitivos de estruturas gramaticais. Nesse sentido, buscamos desenvolver uma intervenção pedagógica de ensino de língua inglesa através da Escrita Colaborativa (EC) no Google Docs para a mobilização de práticas de linguagem no universo digital com alunos de um curso Técnico de Nível Médio Integrado do Instituto Federal de Educação, Ciência e Tecnologia do Rio Grande do Norte. Para isso, fundamentamo-nos nas concepções de que a língua é interação social e mediadora das relações humanas através dos gêneros do discurso (BAKHTIN; VOLOCHÍNOV, 2006). Essa interação é o cerne da Teoria Sociocultural de Vygotsky aplicada à aprendizagem de uma segunda língua (LANTOLF; THORNE, 2007), serve como mediadora da aprendizagem e da escrita colaborativa (SMITH; MACGREGOR, 1992; FUNG, 2006, 2010; ALLEN et al., 1987) e é a premissa do meio escolhido para a operacionalização da proposta de ensino de Escrita Colaborativa Online (ECO) (YIM; WARSCHAUER, 2017; LEANDRO; WEISSHEIMER, 2017; EMILIANO, 2016; KESSLER; BIKOWSKI; BOGGS, 2012). A abordagem do estudo é qualitativa (RICHARDSON, 2016), do tipo intervenção pedagógica (DAMIANI et al., 2013), no qual os alunos escreveram colaborativamente um post de notícia para um blog informativo. Participaram da intervenção 36 alunos, os quais foram divididos em sete grupos de colaboração e se reuniram para a escrita do texto ao longo de três semanas - não consecutivas. O corpus da pesquisa constituiu-se pelas respostas dos questionários aplicados antes e depois da Intervenção, interações do chat e notas de campo do professor. Percebemos que os alunos precisam de mais oportunidades para melhorar a prática de atividades em grupo; problemas sociais podem dificultar o uso da ferramenta digital; a aprendizagem de língua inglesa foi uma consequência da ECO. No que concerne às interações do chat, além de encontrarmos todas as características da EC presencial detectamos mais uma relacionada aos fatores externos de razão social e técnica que podem influenciar a realização da ECO. Sobre a avaliação da intervenção propriamente dita, sugerimos o aprimoramento do método de ensino através do aumento da quantidade de encontros online, a realização do método pelo professor da disciplina e a instrução explícita a respeito de atividades de colaboração.

Fonte: Dantas (2020).

Neste resumo (Figura 2), ao tomarmos a primeira oração constitutiva, percebemos que a professora-pesquisadora tematiza a prática de escrita em língua inglesa na escola pública, avaliando-a negativamente por suas limitações, através do uso da expressão está restrita, e pela ausência de criatividade, através do uso do adjetivo repetitivos. Desse modo, o discurso acadêmico da professora-pesquisadora, ao bivocalizar com o discurso teórico, tanto por meio da inserção do referente no texto (nomeação da Teoria Sociocultural de Vygotsky) quanto por meio da citação indireta a outros estudos, encontra 
formas de responder à tradição de ensino de escrita em língua inglesa de uma forma que leva em consideração as práticas de linguagem no universo digital.

O discurso acadêmico da professora-pesquisadora de inglês se constitui predominantemente ancorado no discurso teórico que concebe a língua enquanto interação social e nos estudos sobre a escrita Colaborativa Online (ECO). No entanto, as relações dialógicas que percebemos não se limitam a uma conformação, pois o discurso acadêmico se propõe a empreender uma complementariedade ao discurso teórico de base, explicitamente evidenciada pela expressão mais uma no excerto: No que concerne às interações do chat, além de encontrarmos todas as características da EC presencial detectamos mais uma relacionada aos fatores externos de razão social e técnica que podem influenciar a realização da ECO. Dessa forma, percebemos que o discurso acadêmico da professora de inglês, ao bivocalizar-se ao discurso teórico, também o faz de maneira crítica, pois o complementa por meio da produção do conhecimento oriundo de interações da pesquisadora com seu contexto mais imediato, que apontam para problemas sociais (fatores externos de razão social e técnica). Assim, embora o discurso acadêmico não contemple de início um interesse explícito em relação a problemas sociais, que em perspectiva de interseccionalidade com raça, gênero social e sexualidade constitui agenda de uma vertente mais radical da LA, questões sociais acabam sendo apontadas, recebendo destaque na pesquisa realizada sobre o ensino de língua inglesa na escola pública. Dada a análise, percebemos a heterogeneidade da composição do discurso acadêmico de professoras-pesquisadoras de inglês, sua inter-relação com discursos teóricos e discursos oficiais sobre o ensino de inglês, e a ausência de um interesse inicial para inter-relacionar o ensino da língua a problemas sociais.

\section{Por mais INdisciplina na escola pública}

Orientado pela prática autorreflexiva continuada da LA, este artigo objetivou investigar como o discurso acadêmico do professor-pesquisador de inglês participa da discussão ideológica sobre o ensino de inglês na escola pública. Por meio da análise dialógica empreendida, foi possível perceber que a criticidade no corpus analisado está relacionada, sobretudo, a práticas de ensino de língua inglesa caracterizadas como tradicionais e a discursos oficiais do contexto mais imediato das professoras-autoras dos textos 
analisados. Em vertente INdisciplinar, com o interesse explícito de criar inteligibilidades sobre práticas situadas e ciente de que minha subjetividade e intersubjetividade me torna inseparável do conhecimento que produzo, optei por explorar 2 resumos de dissertações de mestrado que sintetizam pesquisas sobre o ensino de inglês na escola pública orientadas por mim no último quadriênio - 2017 a 2020 -, de modo que a seleção do corpus se demonstrasse representativa do projeto discursivo.

Por meio da análise, é possível realizar uma (auto)crítica, pois, embora ela evidencie a heterogeneidade da composição do discurso acadêmico das professoraspesquisadoras de inglês e a autonomia desses sujeitos ao realizarem sua investigação de mestrado, ela aponta, também, para uma ausência de interesse inicial em pautar problemas sociais nas investigações sobre o ensino de língua inglesa na escola pública. Embora uma das pesquisas paute questões sobre cidadania e participação social por meio da discussão sobre o derramamento de óleo no litoral do nordeste brasileiro em 2019 e ainda encoraje os estudantes a denunciarem o crime ambiental, esses dados não ficaram evidentes no corpus analisado, o que revela, ainda, a pouca valorização que o discurso acadêmico do professor de inglês atribuiu a esses elementos na composição do seu resumo de dissertação. Por fim, destaco que a vertente INdisciplinar da LA se apresenta como um desafio às novas pesquisas sobre o ensino inglês na escola pública, que talvez esteja precisando de mais INdisciplina, na tentativa de explorar caminhos menos intuitivos, de modo a poder dar visibilidade a pequenas histórias, sem ingenuidades.

\section{Referências}

AMARAL, M. R. S.; SILVA, E. G; GONÇALVES, J. B. C. As contribuições da Linguística Aplicada (LA) e da Análise Dialógica do Discurso (ADD) para pensar a escola como lugar de debate público. RAÍ́DO (ONLINE), Dourados, v. 14, n. 36, p. 355-377, 2020.

BAKHTIN, M. M. Problemas da poética de Dostoiévsky. Tradução de Paulo Bezerra. 5. ed. Rio de Janeiro: Forense Universitária, 2018.

BAKHTIN, M. Os gêneros do discurso. $1^{\mathrm{a}}$ edição. Organização, tradução, posfácio e notas de Paulo Bezerra. Notas da edição russa Serguei Botcharov. São Paulo: Editora $34,2016$. 
BIASI-RODRIGUES, B. Organização retórica de resumos de dissertações. Revista do GELNE (Grupo de Estudos Linguísticos do Nordeste), Fortaleza, v. 1, n. 1, p. 31-37, 1999.

BRAIT, B. (org.). Bakhtin: conceitos-chave. 5 ed. São Paulo: Contexto, 2017.

BRAIT, B. (org.). Bakhtin: outros conceitos-chave. 2 ed. São Paulo: Contexto, 2016.

BRAIT, B. Análise e teoria do discurso. In: BRAIT, B. (org.). Bakhtin: outros conceitos-chave. 2 ed. São Paulo: Contexto, 2016. p. 9-31.

CAETANO, E. A. "But When do I do Critical Literacy?” Perspectives for Designing Critical Literacy Activities in EFL Classrooms. Rev. bras. linguist. apl., Belo Horizonte, v. 20, n. 2, p. 279-300, 2020.

CARNEIRO, K. Z. S. Abordagens críticas sobre o ensino de inglês na escola pública: tendências de pesquisas na RBLA. In: CONGRESSO NORDESTINO DE LINGUÍSTICA APLICADA, 1., 2021, Aracaju. Anais do I Congresso Nordestino de Linguística Aplicada (I CONELA): panorama dos estudos teóricos e práticos em linguística aplicada. Aracaju: Ed. dos Autores, 2021. p. 1025-1038.

CELANI, M. A. A. Transdisciplinaridade na Linguística Aplicada no Brasil. In: SIGNORINI, I.; CAVALCANTI, M. C. (org.). Linguística aplicada e transdisciplinaridade: questões e perspectivas. Campinas, SP: Mercado de Letras, 1998. p. 129-142.

CIAVATTA, M. O ensino integrado, a politecnia e a educação omnilateral: por que lutamos?. Trabalho \& Educação, Belo Horizonte, v. 23, n. 1, p. 187-205, 2014.

DA SILVA, L. Critical tasks in action: the role of the teacher in the implementation of tasks designed from a critical perspective. Ilha do Desterro A Journal of English Language, Literatures in English and Cultural Studies, Florianópolis, v. 73, n. 1, p. 109-128, 2020.

DANTAS, S. G. M. A escrita colaborativa no Google Docs: uma intervenção pedagógica no ensino de língua inglesa. 2020. Dissertação (Mestrado em Ensino) Universidade do Estado do Rio Grande do Norte, Universidade Federal Rural do Semiárido, Instituto Federal de Educação, Ciência e Tecnologia do Rio Grande do Norte, Mossoró, 2017.

FABRÍCIO, B. F. Linguística aplicada como espaço de "desaprendizagem". Redescrições em curso. In: MOITA LOPES, L. P. (org.). Por uma linguística aplicada INdisciplinar. São Paulo: Parábola Editorial, 2006. p. 45-65.

FABRICIO, B. F. Linguística aplicada e visão de linguagem: por uma INdisciplinaridade radical. Rev. bras. linguist. apl., Belo Horizonte, v. 17, n. 4, p. 599$617,2017$. 
FREIRE, P. Pedagogia do oprimido. 67 ed. Rio de Janeiro/São Paulo: Paz e Terra, 2019.

GADOTTI, M. A escola e o professor: Paulo Freire e a paixão de ensinar.1 ed. São Paulo, Publisher Brasil, 2007.

GUERRA, W. T. Ensino de inglês para fins específicos e multiletramentos na oferta técnica da escola pública. 2017. Dissertação (Mestrado em Ensino) - Universidade do Estado do Rio Grande do Norte, Universidade Federal Rural do Semiárido, Instituto Federal de Educação, Ciência e Tecnologia do Rio Grande do Norte, Mossoró, 2017.

HOOKS, B. Teaching to transgress: education as the practice of freedom. New York: Routledge, 1994.

KUMARAVADIVELU, B. Language teacher education for a global society: a modular model for knowing, analyzing, recognizing, doing, and seeing. New York: Routledge, 2012.

KUMARAVADIVELU, B. The Decolonial Option in English Teaching: Can the Subaltern Act? Tesol Quarterly, Michigan, v. 50, n. 1, p. 66-85, 2016.

LIMA, S. C.; BASTOS, R. L. G. A produção de sentido no discurso jornalístico sobre a pandemia de Covid-19 no Brasil. Linguagem em (Dis)curso, Tubarão, v. 21, n. 2, p. 253-265, 2021.

LIMA, S. C.; VIEIRA, F. O papel do livro didático na promoção da autonomia na aprendizagem de inglês. Rev. bras. linguist. apl., Belo Horizonte, v. 20, n. 1, p. 217 $244,2020$.

MOITA LOPES, L. P. (org.). Por uma linguística aplicada INdisciplinar. São Paulo: Parábola Editorial, 2006.

MULICO, L. V. Learning from the subaltern: What does Maria Lindalva teach us about hegemonic-common-sense-ideology and text selection for English language learning materials?. Trab. linguist. apl., Campinas, v. 59, n. 1, p. 129-150, 2020.

PENNYCOOK, A. Applied Linguistics as epistemic assemblage. AILA review, Amsterdam, v. 31, n. 1, p. 113-134, 2018.

PENNYCOOK, A. Global Englishes and Transcultural Flows. New York: Routledge, 2007.

PENNYCOOK, A. Language as a local practice. New York: Routledge, 2010.

PENNYCOOK, A. Uma linguística aplicada transgressiva. In: MOITA LOPES, L. P. (org.). Por uma linguística aplicada INdisciplinar. São Paulo: Parábola Editorial, 2006. p. 67-83. 
RAJAGOPALAN, K. Culture as an experience of identity formation in foreign language learning. Policromias - Revista de Estudos do Discurso, Imagem e Som, Rio de Janeiro, v. 3, n. 2, p. 11-20, 2018.

RAJAGOPALAN, K. Política de ensino de línguas no Brasil: história e reflexões prospectivas. In: MOITA LOPES, L. P. (org.). Linguística aplicada na modernidade recente: festschrift para Antonieta Celani. 1 ed. São Paulo: Parábola, 2013. p. 143-162.

RAJAGOPALAN, K. Repensar o papel da linguística aplicada. In: MOITA LOPES, L. P. (org.). Por uma linguística aplicada INdisciplinar. São Paulo: Parábola Editorial, 2006. p. 149-168.

ROCHA, L. L. Teoria queer e a sala de aula de inglês na escola pública: performatividade, indexicalidade e estilização. 2013. Tese (Doutorado em Linguística Aplicada) - Programa Interdisciplinar de Pós-Graduação em Linguística Aplicada, Universidade Federal do Rio de Janeiro, Rio de Janeiro, 2013.

SZUNDY, P. T. C.; MARTINS, P. S.; MOREIRÃO, D. D. P. A filosofia da linguagem do Círculo de Bakhtin e a LA indisciplinar: diálogos possíveis. RAÍDO (ONLINE), Dourados, v. 14, p. 378-399, 2020.

URZEDA-FREITAS, M. T. Educando para transgredir: reflexões sobre o ensino crítico de línguas estrangeiras/inglês. Trab. linguist. apl., Campinas, v. 51, n. 1, p. 77-97, 2012.

VIEIRA, F.; MARQUES, I; MOREIRA, M. A. Para o desenvolvimento da autonomia com o manual escolar. In: CASTRO, R. V. et al. (org.). Manuais escolares: estatuto, funções, história. Braga: Centro de Estudos em Educação e Psicologia, 1999. p. 527544.

VOLÓCHINOV, V. Marxismo e filosofia da linguagem: problemas fundamentais do método sociológico na ciência da linguagem. $2^{\mathrm{a}}$ edição. Tradução, notas e glossário de Sheila Grillo e Ekaterina Vólkova Américo. São Paulo: Editora 34, 2018.

Recebido em: 07 de julho de 2021 Aceito em: 20 de outubro de 2021

Publicado em novembro de 2021

Samuel de Carvalho Lima

E-mail: samuel.lima@ifrn.edu.br

ORCiD: https://orcid.org/0000-0002-7145-3686

Revista da Anpoll, Florianópolis, v. 52, n. 2, p. 138-156, jun.-out., 2021 | 156 